\title{
Применение полногеномного анализа для определения молекулярных маркеров значимых генетических кластеров Mycobacterium tuberculosis в Poccuu
}

\author{
Мокроусов И.В. ${ }^{1}$, Черняева Е.Н. ${ }^{\text {, , Вязовая А.А. }{ }^{1}, \text { Журавлев В.Ю. }}$
}

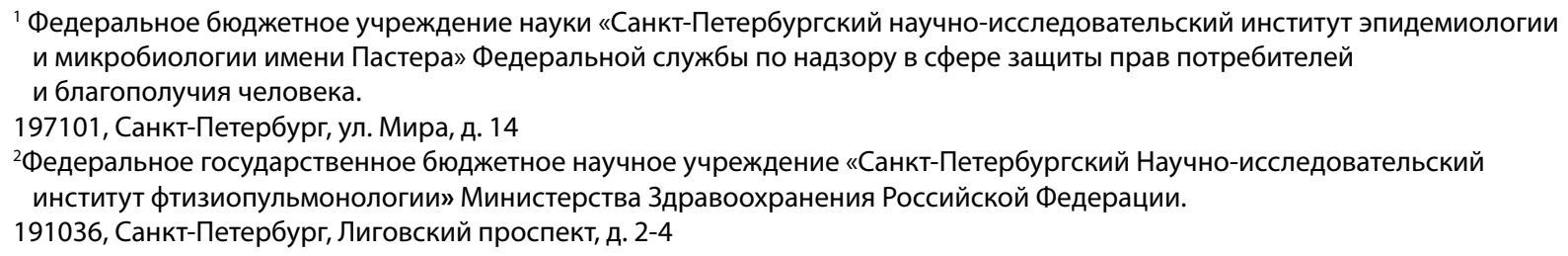

Актуальность. Туберкулёз относят к числу «вновь вернувшихся» заболеваний, получивших эпидемическое распространение во многих регионах мира. Фундаментальный интерес представляет понимание генетических основ aдаnтации возбудителя заболевания Mycobacterium tuberculosis к организму хозяина.

Целью данного исследования было выявление молекулярных маркеров для значимых геновариантов M. tuberculosis в России на основе проведения полногеномного и биоинформационного анализа.

Материалы и методы. Полногеномное секвенирование и филогенетический анализ были проведены для репрезентативной выборки штаммов M. tuberculosis Bосточно-Азиатской линии (древние и современные сублинии генотиna Beijing) и Евро-Американской линии (штаммы генотипов LAM, T и S).

Результаты. В результате филогенетического анализа геномных данных (4500 полиморфных нуклеотидных позиций), были выделены кластеры штаммов и определены их специфические однонуклеотидные полиморфизмы (ОНП, SNP). В частности, внутри сублинии LAM-RUS был выявлен эволючионно «молодой» кластер, включающий штаммы сполиготипов SIT252 и SIT266. Внутри штаммов семейства Веіjіп были выделены ветви современной (субтипы Во и 94-32) и древней сублиний. Среди выявленных кластер-специфических однонуклеотидных полиморфизмов для групп внутри семейств Beijing и LAM наиболее широко были представлены категории генов «процессы, связанные с клеткой и клеточной стенкой» и «промежуточный метаболизм и дыхание». Вариации в генах категории «вирулентность» встречались только в штаммах Beijing BO/W148, древних Beijing и LAM-RUS (SIT252/266).

Выводы. Для эмерджентных, актуально или потенциально эпидемических вариантов M. tuberculosis генотипов LAM и Beijing, выявлены как филогенетически нейтральные, диагностические полиморфизмы, так и мутации в ряде генов вирулентности, адаптации, биосинтеза клеточной стенки, дыхания и липидного обмена.

Ключевые слова: Mусоbacterium tuberculosis; молекулярная эпидемиология; полногеномное секвенирование; генотип Веіjing.

Для цитирования: Мокроусов И.В., Черняева Е.Н., Вязовая А.А., Журавлев В.Ю.Применение полногеномного анализа для определения молекулярных маркеров значимых генетических кластеров Mycobacterium tuberculosis в Poсcии.

Патогенез. 2019; 17(4): 43-49

DOI: $10.25557 / 2310-0435.2019 .04 .43-49$

Для корреспонденции: Мокроусов Игорь Владиславович, e-mail: imokrousov@mail.ru

Финансирование. Исследование получило частичную поддержку Российского фонда фундаментальных исследований (грант 19-04-00263).

Конфликт интересов. Авторы заявляют об отсутствии конфликта интересов.

Поступила: 10.08.2019

\section{The use of whole-genome analysis for identifying molecular markers of significant genetic clusters of Mycobacterium tuberculosis in Russia}

Mokrousov I.V. ${ }^{\text {, }}$ Chernyaeva E.N. ${ }^{1}$, Vyazovaya A.A. ${ }^{1}$, Zhuravlev V.Y. ${ }^{2}$

1 St. Petersburg Pasteur Institute,

Mira Str. 14, St. Petersburg 197101, Russian Federation

2 St. Petersburg State Research Institute of Phthisiopulmonology,

Ligovskiy Prospekt 2-4, St. Petersburg 191036, Russian Federation

Tuberculosis is one of the re-emerging diseases that have epidemically spread in many regions worldwide. Understanding of the genetic basis for Mycobacterium tuberculosis adaptation to the human host is of a fundamental interest.

The aim of this study was to identify molecular markers for significant genetic clusters of M. tuberculosis in Russia based on $a$ whole genome and bioinformatics analysis. Whole genome sequencing and phylogenetic analysis were performed for $a$ representative sample of $M$. tuberculosis strains of the East Asian lineage (ancient and modern sublineages of the Beijing genotype) and the Euro-American lineage (strains of LAM, T and S genotypes). The phylogenetic analysis of genomic data (4500 polymorphic nucleotide positions) allowed to identify strain clusters and to determine their specific single nucleotide polymorphisms (SNPS). Specifically, an evolutionarily "young" cluster was identified within the LAM-RUS branch, including 
strains of the SIT252 and SIT266 spoligotypes. Modern (subtypes BO and 94-32) and ancient sublineages were identified within the Beijing genotype. Beijing and LAM cluster-specific SNPs were mainly found in gene categories "cell wall and cell processes" and "intermediary metabolism and respiration". Variations in the genes of the "virulence" category were found only in strains of Beijing BO/W148, ancient Beijing and LAM-RUS (SIT252/266) groups. To conclude, phylogenetically neutral polymorphisms as well as mutations in virulence, adaptation, cell wall biosynthesis, respiration, and lipid metabolism genes were identified for emerging, potentially epidemic variants of the LAM and Beijing genotypes of M. tuberculosis.

Key words: Mycobacterium tuberculosis, molecular epidemiology, whole genome sequencing, Beijing genotype.

For citation: Mokrousov I.V., Chernyaeva E.N., Vyazovaya A.A., Zhuravlev V.Y. [The use of whole-genome analysis for identifying molecular markers of significant genetic clusters of Mycobacterium tuberculosis in Russia]. Patogenez [Pathogenesis]. 2019; 17(4): 43-49 (in Russian)

DOI: 10.25557/2310-0435.2019.04.43-49

For correspondence: Mokrousov Igor Vladislavovich, e-mail: imokrousov@mail.ru

Funding. This study received partial support from the Russian Foundation for Basic Research (grant 19-04-00263).

Conflict of interest. The authors declare no conflict of interest.

Received: 10.08.2019

\section{Введение}

Туберкулёз (ТБ) относится к числу так называемых «вновь вернувшихся» заболеваний, получивших эпидемическое распространение во многих регионах мира. По оценке ВО3, треть человечества инфицирована Mycobacterium tuberculosis. Возросшая мобильность населения приводит к глобальной диссеминации наиболее опасных мультирезистентных и гипервирулентных штаммов M. tuberculosis. Современные молекулярные методы позволили понять функционирование генома возбудителя туберкулёза M. tuberculosis и оценить эволюцию этого микроорганизма [1]. Для вида M. tuberculosis характерно отсутствие горизонтального генного переноса и, как следствие этого - клональная и иерархическая структура популяции, состоящей, на глобальном уровне, из 8 филогенетических линий, менее крупных генетических семейств и компактных клональных кластеров, которые отличаются по своей клинической и/или эпидемиологической значимости. Некоторые генетические семейства, например, генотип Beijing, широко распространены в различных регионах мира, вероятно, по причине их генетического преимущества $[2,3]$. Генотип разделяют на древние (предковые) и современные сублинии, при этом в России преобладают штаммы современной сублинии, прежде всего, следует отметить эпидемический кластер Beijing В0 [4, 5]. При этом, для штаммов древней сублинии в Японии и Корее ранее были описаны различия в особенностях развития лекарственной устойчивости и степени кластеризации как прокси-маркера трансмиссивности [6-8] и недавно был выявлен резистентный кластер древней сублинии генотипа Beijing в Западной Сибири [9].

M. tuberculosis может адаптироваться к воздействию факторов иммунного ответа организма хозяина и к селективному давлению антибиотиков путем точечных мутаций. В последние годы, благодаря относительной доступности полногеномного секвенирования, стало возможным проведение анализа большого количества геномов клинических изолятов. При этом следует отметить, что зачастую качество анализа и оригиналь- ность выводов существенно отстают от впечатляющего массива обработанных геномных данных. Немалая часть публикуемых статей повторяет старые известные теории, выдвинутые в первое десятилетие 21 века, в частности в том, что касается генетических основ лекарственной устойчивости, роли компенсаторных мутаций, роли генов селекции второго порядка, генов вирулентности.

Фундаментальный интерес представляет понимание того, какие гены и каким образом меняются в процессе ко-адаптации микроорганизма и хозяина, какие факторы эволюции (они же факторы коадаптации с хозяином) определяют текушую и историческую филогеографию возбудителя туберкулёза. Накопление изменений в определенных генах в процессе эволюции отражает его взаимную адаптацию с популяцией человека и происходит по-разному в различных генетических семействах (линиях) M. tuberculosis. Также следует учитывать разные стартовые позиции штаммов на конкретной территории, то есть, является ли штамм (геновариант) историческим или новозанесенным. Возможно, что более древние варианты несут в своих геномах следы более долгой эволюции и коадаптации и характеризуются меньшей вирулентностью и трансмиссивностью. В то же время, у относительно недавно возникших современных геновариантов были различные условия происхождения (в разных человеческих популяциях при разных условиях окружающей среды), и, как следствие этого - разные парадигмы эволюции в сторону большей или пониженной вирулентности и других патогенетических особенностей.

Целью данного исследования было выявление молекулярных маркёров для значимых геновариантов возбудителя туберкулёза в России на основе проведения полногеномного и биоинформационного анализа.

\section{Материалы и методы исследования}

Изоляты M. tuberculosis были получены от больных туберкулёзом лёгких, проживающих в Санкт-Петербурге. Биологический материал собран с письменного 
согласия пациентов Санкт-Петербургского НИИ фтизиопульмонологии, без раскрытия персональных данных (процедура регламентирована Этическим комитетом НИИ фтизиопульмонологии). Идентификация изолятов на уровне вида была проведена с использованием стандартных микробиологических и биохимических тестов.

Экстракция и очистка ДНК бактерий были проведены стандартным методом: обработка клеточного лизата лизоцимом, протеиназой К, цетилтриметиламмоний бромидом и додецилсульфатом натрия для разрушения клеточной стенки и вторичных метаболитов, протеинов и полисахаридов, с последующей экстракцией ДНК с использованием фенола и хлороформа, и осаждением в изопропаноле [10].

Сполиготипирование проводили согласно стандартному протоколу, с использованием мембраны с иммобилизованными олигонуклеотидами на 43 спейcepa локуса CRISPR M. tuberculosis, изготовленной в лаборатории молекулярной микробиологии НИИЭМ им. Пастера $[11,12]$. Профили сполиготипирования сравнивали с международной базой данных SITVIT2 [13].

Для дальнейшего исследования была сформирована репрезентативная выборка штаммов для проведения полногеномного секвенирования (ПГС) эпидемиологически и клинически значимых вариантов и генотипов возбудителя туберкулёза, циркулирующих в России: генотип Beijing (древние и современные штаммы, варианты В0 и А0; все штаммы имели сполиготип SIT1) и генотип $L A M$ (сублинии RD-Rio, $L A M-R U S$, сполиготипы 252, 254, 266). Также были включены штаммы других генотипов в качестве внешней группы (сполиготипы SIT40 и SIT34, относящиеся к Евро-Американской линии).
Полногеномное секвенирование проводили с использованием платформы MiSeq (Illumina), используя реагенты для получения парных прочтений длиной по 300 нуклеотидов. Для подготовки ДНК-библиотек для секвенирования использовали ультразвуковую фрагментацию ДНК и применяли набор NEBNext Ultra DNA Library Prep Kit for Illumina (New England Biolabs). Первичную обработку коротких нуклеотидных прочтений (fastq файлов) проводили с использованием программы Trimmomatic (http://www.usadellab. org/cms/index.php?page=trimmomatic) для удаления адаптеров и нуклеотидных прочтений низкого качества. Полученные файлы использовали для выравнивания на референсный геном M. tuberculosis H37 Rv (NC_000962.3) для дальнейшего поиска геномных вариантов с использованием программы bowtie2, после чего для идентификации и аннотации нуклеотидных полиморфизмов использовали утилиты SAMtools (http://samtools.sourceforge.net). Онлайн-ресурсы Phyresse (https://bioinf.fz-borstel.de/mchips/phyresse/), TGS-TB (https://gph.niid.go.jp/tgs-tb/) и PhyTB (http:// pathogenseq.lshtm.ac.uk/phytblive/index.php) использовали для дополнительной классификации секвенированных геномов.

\section{Результаты исследования и обсуждение}

Филогенетический анализ данных, полученных в результате полногеномного секвенирования, был проведен для коллекции штаммов, которая включала 19 штаммов Beijing (древние и современные сублинии), 11 штаммов LAM (сублинии RD-Rio, LAM-RUS), 2 штамма семейства $T$ (сполиготип SIT40) и 1 штамм семейства $S$. В результате филогенетического анализа геномных данных (4500 полиморфных нуклеотидных

Таблица 1

Распределение однонуклеотидных полиморфизмов, специфичных для подгрупп внутри генотипов Beijing и $L A M$

\begin{tabular}{|c|c|c|c|c|c|c|}
\hline $\begin{array}{c}\text { Функциональная категория } \\
\text { (по Tuberculist EPFL) }\end{array}$ & $\begin{array}{l}\text { Beijing, современ- } \\
\text { ная сублиния, } \\
\text { В0-кластер }\end{array}$ & $\begin{array}{l}\text { Beijing, современ- } \\
\text { ная сублиния, А0- } \\
\text { кластер }\end{array}$ & $\begin{array}{c}\text { Beijing, ранняя } \\
\text { древняя } \\
\text { сублиния }\end{array}$ & $\begin{array}{l}\text { LAM-RUS, } \\
\text { SIT252/266- } \\
\text { кластер }\end{array}$ & $\begin{array}{l}\text { LAM-RUS, } \\
\quad \text { SIT252 }\end{array}$ & $\begin{array}{l}L A M-R U S \\
\text { SIT266 }\end{array}$ \\
\hline $\begin{array}{l}\text { Процессы, связанные } \\
\text { с клеткой и клеточной } \\
\text { стенкой }\end{array}$ & 16 & 5 & 15 & 5 & 2 & 1 \\
\hline $\begin{array}{l}\text { Консервативные гипоте- } \\
\text { тические белки }\end{array}$ & 18 & 2 & 2 & 5 & 1 & 1 \\
\hline $\begin{array}{l}\text { Промежуточный метабо- } \\
\text { лизм и дыхание }\end{array}$ & 21 & 4 & 31 & 9 & 1 & 3 \\
\hline Липидный метаболизм & 2 & 4 & 12 & 2 & 2 & 1 \\
\hline Информационные пути & 2 & 3 & 5 & 4 & & 2 \\
\hline Регуляторные белки & 4 & 1 & & 1 & & \\
\hline Стабильные РНК & & & & 1 & & \\
\hline $\begin{array}{l}\text { Вирулентность, детокси- } \\
\text { фикация, адаптация }\end{array}$ & 3 & & 10 & 1 & & \\
\hline Всего снипов & 66 & 19 & 78 & 28 & 6 & 8 \\
\hline
\end{tabular}


Характеристика полиморфизмов, специфичных для кластера штаммов ранней древней сублинии генотипа Beijing

\begin{tabular}{|c|c|c|c|}
\hline Ген & $\begin{array}{l}\text { Позиция } \\
\text { в геноме и } \\
\text { мутация }\end{array}$ & $\begin{array}{c}\text { Продукт гена } \\
\text { (согласно https://mycobrowser.epfl.ch/) }\end{array}$ & $\begin{array}{c}\text { Функциональная категория } \\
\text { (согласно https://mycobrowser.epfl.ch/) }\end{array}$ \\
\hline $\operatorname{dnaN}$ & $3170 \mathrm{~A}>\mathrm{G}$ & ДНК полимераза III & Информационные пути \\
\hline $\operatorname{acp} A$ & $36813 \mathrm{~A}>\mathrm{G}$ & Ацилпереносящий белок АсрА & Липидный метаболизм \\
\hline$n r p$ & $114980 \mathrm{C}>\mathrm{A}$ & Пептидсинтетаза Nrp & Липидный метаболизм \\
\hline $\operatorname{gmh} B$ & $138029 \mathrm{C}>\mathrm{A}$ & D-глицеро-D-манно-гептоз 7-фосфаткиназа & Процессы, связанные с клеткой и клеточной стенкой \\
\hline oxcA & $143030 \mathrm{C}>\mathrm{A}$ & Вероятная оксалил-СоА декарбоксилаза & Промежуточный метаболизм и дыхание \\
\hline$y r b E 1 B$ & $198212 \mathrm{C}>\mathrm{A}$ & Консервативный мембранный белок YrbE1B & Вирулентность, детоксификация, адаптация \\
\hline $\operatorname{lprK}$ & $204840 \mathrm{C}>\mathrm{A}$ & Липопротеин Мсе1Е семейства Мсе & Процессы, связанные с клеткой и клеточной стенкой \\
\hline mmpL11 & $238686 \mathrm{C}>\mathrm{A}$ & $\begin{array}{l}\text { Вероятный консервативный трансмембранный } \\
\text { транспортный белок MmpL11 }\end{array}$ & Процессы, связанные с клеткой и клеточной стенкой \\
\hline vapB25 & $333363 \mathrm{C}>\mathrm{A}$ & Возможный антитоксин VapB25 & Вирулентность, детоксификация, адаптация \\
\hline$r m l A$ & $398918 \mathrm{C}>\mathrm{A}$ & dTDP-глюкозпирофосфорилаза & Промежуточный метаболизм и дыхание \\
\hline dnaJ1 & $423459 \mathrm{C}>\mathrm{A}$ & Вероятный белок-шаперон DnaJ1 & Вирулентность, детоксификация, адаптация \\
\hline fadD30 & $484395 \mathrm{C}>\mathrm{A}$ & АМФ синтетаза жирных кислот & Липидный метаболизм \\
\hline thiG & $502406 \mathrm{C}>\mathrm{A}$ & Белок биосинтеза тиазола & Промежуточный метаболизм и дыхание \\
\hline$c t p H$ & $513669 \mathrm{C}>\mathrm{A}$ & $\begin{array}{l}\text { Возможная катион-траснпортирующая АТФ-а- } \\
\text { за СtpH }\end{array}$ & Процессы, связанные с клеткой и клеточной стенкой \\
\hline$m m p L 2$ & $599670 \mathrm{C}>\mathrm{A}$ & $\begin{array}{l}\text { Вероятный консервативный трансмембранный } \\
\text { транспортный белок MmpL2 }\end{array}$ & Процессы, связанные с клеткой и клеточной стенкой \\
\hline $\operatorname{men} E$ & $634983 \mathrm{C}>\mathrm{A}$ & О-сукцинил бензоат-СоА синтаза & Промежуточный метаболизм и дыхание \\
\hline cyp $135 B 1$ & $660338 \mathrm{C}>\mathrm{A}$ & Возможный цитохром Р450 135В1 & Промежуточный метаболизм и дыхание \\
\hline phoP & $851844 \mathrm{C}>\mathrm{A}$ & транскрипционный регулятор PhoP & Регуляторные протеины \\
\hline$a d h B$ & $855199 \mathrm{C}>\mathrm{A}$ & $\begin{array}{l}\text { Возможная цинксодержащая алкогольдегидро- } \\
\text { геназа НАД-зависимаяt AdhB }\end{array}$ & Промежуточный метаболизм и дыхание \\
\hline $\operatorname{lp} q U$ & $1143997 \mathrm{C}>\mathrm{A}$ & вероятный консервативный липопротеин LpqU & Процессы, связанные с клеткой и клеточной стенкой \\
\hline $\operatorname{coaA}$ & $1219871 \mathrm{C}>\mathrm{A}$ & Киназа пантотеновой кислоты & Промежуточный метаболизм и дыхание \\
\hline $\operatorname{glp} X$ & $1228027 \mathrm{C}>\mathrm{G}$ & Фруктоз-1,6-бисфосфатаза GlpX & Промежуточный метаболизм и дыхание \\
\hline metE & $1259241 \mathrm{C}>\mathrm{G}$ & Метионин синтаза & Промежуточный метаболизм и дыхание \\
\hline$m m p L 13 b$ & $1273756 \mathrm{C}>\mathrm{G}$ & $\begin{array}{l}\text { Вероятный консервативный трансмембранный } \\
\text { транспортный белок MmpL13b }\end{array}$ & Процессы, связанные с клеткой и клеточной стенкой \\
\hline fadD6 & $1349375 \mathrm{C}>\mathrm{G}$ & СоА синтетаза жирных кислот & Липидный метаболизм \\
\hline atpH & $1462302 \mathrm{C}>\mathrm{G}$ & Дельта цепь АТФ-синтазы АtpH & Промежуточный метаболизм и дыхание \\
\hline rpoZ & $1565158 \mathrm{C}>\mathrm{G}$ & ДНК-зависимая РНК-полимераза (цепь омега) & Информационные пути \\
\hline priA & $1578856 \mathrm{C}>\mathrm{G}$ & Фактор репликации Y & Информационные пути \\
\hline$w b b L 2$ & $1720081 \mathrm{C}>\mathrm{G}$ & Рамнозилтрансфераза WbbL2 & Консервативные гипотетические белки \\
\hline$c y c A$ & $1930895 \mathrm{C}>\mathrm{T}$ & $\begin{array}{l}\text { D-серин/аланин/глицин транспортерный белок } \\
\text { СусA }\end{array}$ & Процессы, связанные с клеткой и клеточной стенкой \\
\hline pknE & $1970117 \mathrm{C}>\mathrm{T}$ & Трансмембранная серин-треонин киназа Е & Регуляторные протеины \\
\hline$t p x$ & $2183527 \mathrm{C}>\mathrm{T}$ & тиолпероксидаза Трх & Вирулентность, детоксификация, адаптация \\
\hline$y r b E 3 B$ & $2209121 \mathrm{C}>\mathrm{T}$ & $\begin{array}{l}\text { Консервативный гипотетический интегральный } \\
\text { мембранный белок YrbE3B }\end{array}$ & Вирулентность, детоксификация, адаптация \\
\hline $\operatorname{ctp} G$ & $2235800 \mathrm{C}>\mathrm{T}$ & $\begin{array}{l}\text { АТФ-аза G метал-катионного транспортера } \\
\text { Р-типа }\end{array}$ & Процессы, связанные с клеткой и клеточной стенкой \\
\hline hspX & $2278544 \mathrm{C}>\mathrm{T}$ & Белок теплового шока НspX & Вирулентность, детоксификация, адаптация \\
\hline acg & $2279152 \mathrm{C}>\mathrm{T}$ & Консервативный белок Acg & Консервативные гипотетические белки \\
\hline
\end{tabular}

$\overline{\text { Продолжение табл. см. на стр. } 47}$ 


\begin{tabular}{|c|c|c|c|}
\hline Ген & $\begin{array}{l}\text { Позиция } \\
\text { в геноме и } \\
\text { мутация }\end{array}$ & $\begin{array}{c}\text { Продукт гена } \\
\text { (согласно https://mycobrowser.epfl.ch/) }\end{array}$ & $\begin{array}{c}\text { Функциональная категория } \\
\text { (согласно https://mycobrowser.epfl.ch/) }\end{array}$ \\
\hline $\operatorname{lip} T$ & $2290732 \mathrm{C}>\mathrm{T}$ & карбоксилэстераза LipT & Промежуточный метаболизм и дыхание \\
\hline$m p a$ & $2376100 \mathrm{C}>\mathrm{T}$ & микобатериальная протеасомная АТФ-аза & Процессы, связанные с клеткой и клеточной стенкой \\
\hline uspA & $2589661 \mathrm{C}>\mathrm{T}$ & $\begin{array}{l}\text { Сахар-транспортирующий мембранный бе- } \\
\text { лок-АBC-транспортер UspA }\end{array}$ & Процессы, связанные с клеткой и клеточной стенкой \\
\hline cys $K 1$ & $2609013 \mathrm{C}>\mathrm{T}$ & О-ацетилсерин сульфгидролаза А & Промежуточный метаболизм и дыхание \\
\hline moeW & $2613117 \mathrm{C}>\mathrm{T}$ & Белок биосинтеза молибдоптерина MoeW & Промежуточный метаболизм и дыхание \\
\hline amiA2 & $2644643 \mathrm{C}>\mathrm{T}$ & амидаза AmiA2 & Промежуточный метаболизм и дыхание \\
\hline mbtJ & $2678523 \mathrm{C}>\mathrm{T}$ & Возможная ацетилгидролаза MbtJ & Липидный метаболизм \\
\hline vapC19 & $2869016 \mathrm{C}>\mathrm{T}$ & токсин VapC19 & Вирулентность, детоксификация, адаптация \\
\hline relA & $2908252 \mathrm{C}>\mathrm{T}$ & ГТФ-пирофосфокиназа RelA & Промежуточный метаболизм и дыхание \\
\hline speE & $2928883 \mathrm{C}>\mathrm{T}$ & спермидинсинтаза SpeE & Промежуточный метаболизм и дыхание \\
\hline $\operatorname{sth} A$ & $3026472 \mathrm{C}>\mathrm{T}$ & Растворимая пиридин трансгидрогеназа SthA & Промежуточный метаболизм и дыхание \\
\hline$m q o$ & $3161688 \mathrm{C}>\mathrm{T}$ & Малат-хинолон оксидоредуктаза Мqо & Промежуточный метаболизм и дыхание \\
\hline relF & $3177660 \mathrm{C}>\mathrm{T}$ & атитоксин RelF & Вирулентность, детоксификация, адаптация \\
\hline $\operatorname{viu} B$ & $3204720 \mathrm{C}>\mathrm{T}$ & Белок утилизации микобактина ViuB & Промежуточный метаболизм и дыхание \\
\hline$g \ln D$ & $3228926 \mathrm{G}>\mathrm{T}$ & РІІ уридил-трансфераза & Промежуточный метаболизм и дыхание \\
\hline ppsA & $3245756 \mathrm{G}>\mathrm{T}$ & поликедитсинтаза PpsA & Липидный метаболизм \\
\hline pps $D$ & $3266769 \mathrm{G}>\mathrm{T}$ & поликетидсинтаза ppsD & Липидный метаболизм \\
\hline mas & $3281726 \mathrm{G}>\mathrm{T}$ & $\begin{array}{l}\text { Мембран-ассоциированная многофункцио- } \\
\text { нальная синтетаза микосерозовой кислоты }\end{array}$ & Липидный метаболизм \\
\hline fadD22 & $3299852 \mathrm{G}>\mathrm{T}$ & Р-гидробензоил-АМФ-лигаза & Липидный метаболизм \\
\hline moaC1 & $3479299 \mathrm{G}>\mathrm{T}$ & $\begin{array}{l}\text { протеин С биосинтеза молибденового кофак- } \\
\text { тора }\end{array}$ & Промежуточный метаболизм и дыхание \\
\hline fbiA & $3640879 \mathrm{~T}>\mathrm{C}$ & Белок биосинтеза F420 & Промежуточный метаболизм и дыхание \\
\hline$p c d$ & $3674012 \mathrm{~T}>\mathrm{C}$ & $\begin{array}{l}\text { дегидрогеназа пиперидин-6-карбоксиловой } \\
\text { кислоты }\end{array}$ & Промежуточный метаболизм и дыхание \\
\hline lhr & $3679378 \mathrm{~T}>\mathrm{C}$ & АТФ-зависимая хеликаза & Информационные пути \\
\hline ats $B$ & $3683721 \mathrm{~T}>\mathrm{C}$ & арилсульфатаза & Промежуточный метаболизм и дыхание \\
\hline $\operatorname{moaX}$ & $3709528 \mathrm{~T}>\mathrm{C}$ & белок слияния MoaD-MoaE & Промежуточный метаболизм и дыхание \\
\hline otsB2 & $3787027 \mathrm{~T}>\mathrm{C}$ & Трегалоз-6-фосфат фосфатаза OtsB2 & Вирулентность, детоксификация, адаптация \\
\hline amiD & $3789601 \mathrm{~T}>\mathrm{C}$ & ацилаза & Промежуточный метаболизм и дыхание \\
\hline eccD4 & $3868372 \mathrm{~T}>\mathrm{C}$ & консервативный компонент EccD4 белка ESX & Процессы, связанные с клеткой и клеточной стенкой \\
\hline eccD4 & $3869537 \mathrm{~T}>\mathrm{C}$ & консервативный компонент EccD4 белка ESX & Процессы, связанные с клеткой и клеточной стенкой \\
\hline $\operatorname{truA}$ & $3876244 \mathrm{~T}>\mathrm{C}$ & урацигидролаза & Информационные пути \\
\hline fadE31 & $4003296 \mathrm{~T}>\mathrm{C}$ & ацил-СоА дегидролаза & Липидный метаболизм \\
\hline ask & $4153340 \mathrm{~T}>\mathrm{C}$ & аспартаткиназа & Промежуточный метаболизм и дыхание \\
\hline pks 13 & $4260414 \mathrm{~T}>\mathrm{C}$ & поликетидсинтаза & Липидный метаболизм \\
\hline fadD23 & $4301135 \mathrm{~T}>\mathrm{C}$ & АМФ-синтетаза жирных кислот & Липидный метаболизм \\
\hline$g l p Q 1$ & $4315532 \mathrm{~T}>\mathrm{G}$ & глицеринфосфодиэфирфосфодиэстераза & Промежуточный метаболизм и дыхание \\
\hline glt $D$ & $4330177 \mathrm{~T}>\mathrm{G}$ & L-глутамат синтетаза & Промежуточный метаболизм и дыхание \\
\hline whiB6 & $4338326 \mathrm{~T}>\mathrm{G}$ & Регуляторный белок WhiB & Регуляторные протеины \\
\hline $\operatorname{esp} K$ & $4358125 \mathrm{~T}>\mathrm{G}$ & секреторный белок ESX-1 & Процессы, связанные с клеткой и клеточной стенкой \\
\hline $\operatorname{esp} B$ & $4360997 \mathrm{~T}>\mathrm{G}$ & Секретируемый субстрат протеина ESX-1 & Процессы, связанные с клеткой и клеточной стенкой \\
\hline eccC2 & $4376444 \mathrm{~T}>\mathrm{G}$ & Белок ESX-2 VII типа & Процессы, связанные с клеткой и клеточной стенкой \\
\hline $\operatorname{tr} x B 2$ & $4401802 \mathrm{~T}>\mathrm{G}$ & Тиоредоксин редуктаза & Промежуточный метаболизм и дыхание \\
\hline
\end{tabular}


позиций), были выделены кластеры штаммов и определены их специфические однонуклеотидные полиморфизмы (ОНП, SNP). В частности, внутри сублинии LAM-RUS был выявлен эволюционно «молодой» кластер, включающий штаммы сполиготипов SIT252 и SIT266. Внутри штаммов семейства Beijing были выделены ветви современной (субтипы В0 и 94-32) и древней сублиний.

Картирование коротких геномных прочтений на референсный геном штамма $\mathrm{H} 37 \mathrm{Rv}$ позволило определить наличие крупной делеции $R D 181$ в геномах штаммов древних Beijing, т.е., они относились к несколько более поздней подгруппе ранних древних Beijing, coгласно модифицированной эволюционной схеме для генотипа Beijing [14]. Анализ других штаммов выявил крупные геномные делеции для штаммов $L A M$, разделяющие их на две основные сублинии $R D 174 / R D-R i o$ и $R D 115$.

Соотнесение всего массива SNP, выявленных в изученных штаммах с известными генами, играющими роль в патогенезе и адаптации возбудителя туберкулёза, выявило кластер-специфические однонуклеотидные полиморфизмы для групп внутри семейств Beijing и $L A M$ (табл. 1).

Наибольшее количество вариаций выявлено в штаммах эволюционно «молодых» генетического кластера Beijing B0/W148 и кластера LAM-RUS (сполиготипы SIT252, SIT266), но также и у штаммов древней сублинии Beijing. Большее количество ОНП (78) штаммов древней сублинии Beijing (табл. 2) может быть связано с их более длительной эволюцией. Также это может коррелировать с недавним выявлением высокорезистентного кластера ранней древней сублинии Beijing в Омской области Сибири [9] и описанием таких штаммов, выделенных от больных туберкулёзным спондилитом на Северо-Западе России [15].

Среди генов, содержащих кластер-специфические полиморфизмы, наиболее широко были представлены категории генов «процессы, связанные с клеткой и клеточной стенкой» и «промежуточный метаболизм и дыхание». Вариации в генах категории «вирулентность» встречались гораздо реже и только в штаммах Beijing B0/W148, древней сублинии Beijing и LAM-RUS (SIT252/266). Накопление определенного набора мутаций в патогенетически значимых локусах (и протеинах) может иметь отношение к особенностям «успешности» таких штаммов, представляющих эпидемические клоны возбудителя туберкулёза.

Анализ других типов мутаций (помимо однонуклеотидных замен) выявил потенциальные мутации сдвига рамки, как результат инсерций/делеций (инделов). Полиморфизмы, связанные с короткими инделами, чаще встречались в группах генов PE-PGRS, PPE (мультигенные полиморфные семейства с точно не определенными функциями) [16] и/или в межгенных участках. Анализ полиморфизма, ведущего к возможному сдвигу рамки считывания в результате коротких
(1-5 нуклеотидов) делеций или инсерций показал относительное преобладание таких мутаций у штаммов геноварианта Beijing B0/W148 (гены Rv1995, Rv0888, Rv1028c/kdpD, Rv3434c) и только двух мутаций у геноварианта Beijing 94-32 (Rv0888, Rv1971/mce3F). Особое внимание обращают на себя гены kdpD и mce3F. Ген $\mathrm{kdpD}$ относится к категории регуляторных белков; согласно ресурсу Tuberculist, он явялется членом двухкомпонентной регуляторной системы KDPD/KDPE и принадлежит к группе белков универсального стресca, ранее была сформулирована гипотеза о его роли в эволюции генотипа W148 [17]. Ген mсе3F относится к функциональной категории «вирулентность, детоксификация, адаптация», также полагают, что белки Мсе связаны с проникновением в клетку хозяина [18].

\section{Заключение}

Таким образом, для эмерджентных, актуально или потенциально эпидемических вариантов M. tuberculosis генотипов LAM и Beijing, выявлены как филогенетически нейтральные, диагностические полимофизмы, так и мутации в ряде генов вирулентности, адаптации, биосинтеза клеточной стенки, дыхания и липидного обмена.

Ввиду значительного количества полиморфизмов у кластера российских штаммов древней сублинии генотипа Beijing, в том числе, в генах вирулентности, не исключено их эпистатическое взаимодействие, ведущее в повышенной трансмиссивности и вирулентности, но для подтверждения этой гипотезы необходимы дальнейшие исследования с использованием экспериментальных моделей.

\section{Список литературы / References}

1. Brosch R., Gordon SV., Marmiesse M., Brodin P., Buchrieser C., Eiglmeier K., Garnier T., Gutierrez C., Hewinson G., Kremer K., Parsons LM., Pym AS., Samper S., van Soolingen D., Cole S.T. A new evolutionary scenario for the Mycobacterium tuberculosis complex. Proc. Natl. Acad. Sci. USA. 2002; 99(6): 3684-3689. DOI: 10.1073/ pnas. 052548299

2. Hanekom M., Gey van Pittius N.C., McEvoy C., Victor T.C., Van Helden P.D., Warren R.M. Mycobacterium tuberculosis Beijing genotype: a template for success. Tuberculosis (Edinb). 2011; 91(6): 510523. DOI: $10.1016 /$ j.tube.2011.07.005

3. Parwati I., van Crevel R., van Soolingen D. Possible underlying mechanisms for successful emergence of the Mycobacterium tuberculosis Beijing genotype strains. Lancet Infect Dis. 2010; 10(2): 103111. DOI: $10.1016 / \mathrm{S} 1473-3099(09) 70330-5$

4. Mokrousov I. Insights into the origin, emergence, and current spread of a successful Russian clone of Mycobacterium tuberculosis. Clin. Microbiol. Rev. 2013; 26(2): 342-360. DOI: 10.1128/CMR.00087-12

5. Mokrousov I. Mycobacterium tuberculosis phylogeography in the context of human migration and pathogen's pathobiology: Insights from Beijing and Ural families. Tuberculosis (Edinb). 2015; $95 \mathrm{Suppl}$ 1: 167-176. DOI: 10.1016/j.tube.2015.02.031

6. Iwamoto T., Yoshida S., Suzuki K., Wada T. Population structure analysis of the Mycobacterium tuberculosis Beijing family indicates an association between certain sublineages and multidrug resistance. Antimicrob. Agents Chemother. 2008; 52: 3805-3809. DOI: 10.1128/ AAC.00579-08

7. Maeda S., Hang N.T., Lien L.T., Thuong P.H., Hung N.V., Hoang N.P., Cuong V.C., Hijikata M., Sakurada S., Keicho N. Mycobac- 
terium tuberculosis strains spreading in Hanoi., Vietnam: Beijing sublineages, genotypes, drug susceptibility patterns, and host factors. Tuberculosis (Edinb). 2014; 94: 649-956. DOI: 10.1016/j. tube.2014.09.005

8. Shamputa I.C., Lee J., Allix-Béguec C., Cho E.J., Lee J.I., Rajan V., Lee E.G., Min J.H., Carroll M.W., Goldfeder L.C., Kim J.H., Kang H.S., Hwang S., Eum S.Y., Park S.K., Lee H., Supply P., Cho S.N., Via L.E., Barry C.E. 3rd. Genetic diversity of Mycobacterium tuberculosis isolates from a tertiary care tuberculosis hospital in South Korea. J. Clin. Microbiol. 2010; 48: 387-394. DOI: 10.1128/ JCM.02167-09

9. Mokrousov I., Vyazovaya A., Pasechnik O., Gerasimova A., Dymova M., Chernyaeva E., Tatarintseva M., Stasenko V. Early ancient sublineages of Mycobacterium tuberculosis Beijing genotype: unexpected clues from phylogenomics of the pathogen and human history. Clin. Microbiol. Infect. 2019; 25(8): 1039.e1-1039.e6. DOI: 10.1016/j. cmi.2018.11.024

10. van Embden J., Cave M., Crawford J., Dale J.W., Eisenach K.D., Gicquel B., Small P. Strain identification on Mycobacterium tuberculosis by DNA fingerprinting: recommendations for a standardized methodology. J. Clin. Microbiol. 1993; 31: 406-409.

11. Kamerbeek J., Schouls L., Kolk A., van Agterveld M., van Soolingen D., Kuijper S., Bunschoten A., Molhuizen H., Shaw R., Goyal M., van Embden J. Simultaneous detection and strain differentiation of Mycobacterium tuberculosis for diagnosis and epidemiology. J. Clin. Microbiol. 1997; 35(4): 907-14.

12. Mokrousov I., Rastogi N. Spacer-Based Macroarrays for CRISPR Genotyping. Methods Mol Biol. 2015; 1311: 111-131. DOI: 10.1007/978-1-4939-2687-9_7

13. Couvin D., David A., Zozio T., Rastogi N. Macro-geographical specificities of the prevailing tuberculosis epidemic as seen through SITVIT2., an updated version of the Mycobacterium tuberculo- sis genotyping database. Infect. Genet. Evol. 2019; 72: 31-43. DOI: 10.1016/j.meegid.2018.12.030

14. Yin Q.Q., Liu H.C., Jiao W.W., Li Q.J., Han R., Tian J.L., Liu Z.G., Zhao X.Q., Li Y.J., Wan K.L., Shen A.D., Mokrousov I. Evolutionary History and Ongoing Transmission of Phylogenetic Sublineages of Mycobacterium tuberculosis Beijing Genotype in China. Sci. Rep. 2016; 6: 34353. DOI: 10.1038/srep34353

15. Vyazovaya A., Mokrousov I., Solovieva N., Mushkin A., Manicheva O., Vishnevsky B., Zhuravlev V., Narvskaya O. Tuberculous spondylitis in Russia and prominent role of multidrug-resistant clone Mycobacterium tuberculosis Beijing B0/W148. Antimicrob. Agents Chemother. 2015; 59(4): 2349-2357. DOI: 10.1128/AAC.04221-14

16. Brennan M.J. The Enigmatic PE/PPE Multigene Family of Mycobacteria and Tuberculosis Vaccination. Infect. Immun. 2017; 85(6): e00969-16. DOI: 10.1128/IAI.00969-16

17. Merker M., Blin C., Mona S., Duforet-Frebourg N., Lecher S., Willery E., Blum M.G., Rüsch-Gerdes S., Mokrousov I., Aleksic E., Allix-Béguec C., Antierens A., Augustynowicz-Kopeć E., Ballif M., Barletta F., Beck H.P., Barry C.E 3rd., Bonnet M., Borroni E., Campos-Herrero I., Cirillo D., Cox H., Crowe S., Crudu V., Diel R., Drobniewski F., Fauville-Dufaux M., Gagneux S., Ghebremichael S., Hanekom M., Hoffner S., Jiao W.W., Kalon S., Kohl T.A., Kontsevaya I., Lillebæk T., Maeda S., Nikolayevskyy V., Rasmussen M., Rastogi N., Samper S., Sanchez-Padilla E., Savic B., Shamputa I.C., Shen A., Sng L.H., Stakenas P., Toit K., Varaine F., Vukovic D., Wahl C., Warren R., Supply P., Niemann S., Wirth T. Evolutionary history and global spread of the Mycobacterium tuberculosis Beijing lineage. Nat. Genet. 2015; 47(3): 242-249. DOI: $10.1038 /$ ng. 3195

18. Zhang F., Xie J.P. Mammalian cell entry gene family of Mycobacterium tuberculosis. Mol Cell Biochem. 2011; 352(1-2): 1-10. DOI: $10.1007 / \mathrm{s} 11010-011-0733-5$

\section{Сведения об авторах:}

Мокроусов Игорь Владиславович - доктор биологических наук, заведующий лабораторией молекулярной эпидемиологии и эволюционной генетики Федерального бюджетного учреждения науки «Санкт-Петербургский научно-исследовательский институт эпидемиологии и микробиологии имени Пастера» Федеральной службы по надзору в сфере защиты прав потребителей и благополучия человека; https://orcid. org/0000-0001-5924-0576

Черняева Екатерина Николаевна - кандидат биологических наук, старший научный сотрудник лаборатории молекулярной эпидемиологии и эволюционной генетики Федерального бюджетного учреждения науки «Санкт-Петербургский научно-исследовательский институт эпидемиологии и микробиологии имени Пастера» Федеральной службы по надзору в сфере защиты прав потребителей и благополучия человека; https://orcid.org/0000-0002-8306-3466

Вязовая Анна Александровна - кандидат биологических наук, старший научный сотрудник лаборатории молекулярной эпидемиологии и эволюционной генетики Федерального бюджетного учреждения науки «Санкт-Петербургский научно-исследовательский институт эпидемиологии и микробиологии имени Пастера» Федеральной службы по надзору в сфере защиты прав потребителей и благополучия человека; https://orcid.org/0000-0001-9140-8957

Журавлев Вячеслав Юрьевич - кандидат биологических наук, руководитель направления «Лабораторная диагностика» Федерального государственного бюджетного научного учреждения «Санкт-Петербургский Научно-исследовательский институт фтизиопульмонологии» Министерства Здравоохранения Российской Федерации; https://orcid.org/0000-0001-6906-6225 